7th International Symposium on Superalloy 718 and Derivatives Edited by: E.A. Ott, J.R. Groh, A. Banik, I. Dempster, T.P. Gabb, R. Helmink, X. Liu, A. Mitchell, G.P. Sjöberg, and A. Wusatowska-Sarnek TMS (The Minerals, Metals \& Materials Society), 2010

\title{
EFFECTS OF AL AND TI ON HAYNES 282 WITH FIXED GAMMA PRIME CONTENT
}

\author{
Paul D. Jablonski ${ }^{1}$, Christopher J. Cowen ${ }^{1}$, and Jeffery A. Hawk ${ }^{1}$ \\ ${ }^{1}$ National Energy Technology Laboratory \\ 1450 Queen Avenue SW, Albany, OR 97321 United States
}

Keywords: Advanced Ultra Supercritical, Steam Turbine, Superalloy, Casting, Homogenization, Creep, Haynes 282

\begin{abstract}
ABSRACT
Traditionally, high temperature components within coal fired power plants are manufactured from ferritic/martensitic steels. However, the proposed steam temperature in the Advanced Ultra Supercritical (A-USC) power plant is high enough $\left(760^{\circ} \mathrm{C}\right.$ ) that ferritic/martensitic steels will not work due to temperature limitations of this class of materials; thus Ni-based superalloys are being considered. The life cycle requirements of such alloys are very demanding and are on the order of several hundred thousand hours. In this paper a wrought Ni-based superalloy with a fixed amount of gamma prime strengthening phase will be examined, with either low Al or low Ti contents, but still within the alloy 282 nominal chemistry specification. The effect that these changes have on the gamma prime misfit and its relevance to long-term microstructural and creep strength stability will be explored both experimentally as well as with computational thermodynamics.
\end{abstract}

\section{Introduction}

Conventional coal-fired power plants utilize steam turbines to generate electricity and operate at efficiencies on the order of 35-37\% [1]. Operation at higher temperatures and pressures can lead to greater efficiencies, resulting in reduced fuel consumption and lower greenhouse gas emissions [2]. The goals of the U.S. Department of Energy's Advanced Power Systems Initiatives include Advanced Ultra Supercritical (A-USC) power generation from coal which requires steam conditions of up to $760^{\circ} \mathrm{C}$ and $35 \mathrm{MPa}$ [3]. Such systems have the ability to reach efficiencies on the order of $47 \%$. Higher efficiency will translate to reduced $\mathrm{CO}_{2}$ production for the same amount of energy produced, thereby facilitating a reduction in green house gas emissions, or if combined with carbon capture and sequestration, there will be less $\mathrm{CO}_{2}$ to capture and sequester. The terms subcritical, supercritical (SC), ultra-supercritical (USC), and AUSC for coal power plants are defined as follows: subcritical at below $22 \mathrm{MPa}$ and $375^{\circ} \mathrm{C}, \mathrm{SC}$ at above $22.1 \mathrm{MPa}$ and 538 to $565^{\circ} \mathrm{C}$, USC at above $565^{\circ} \mathrm{C}$, and A-USC is above temperatures where nickel base superalloys must be used, $\sim 675^{\circ} \mathrm{C}$ [1]. Nickel base superalloys are required in A-USC conditions that exist in both the boiler and the turbine due to high temperature creep strength requirements in these pressurized systems [3].

One of the leading candidate alloys for both boiler and turbine application is Haynes alloy 282, due to its favorable combination of processability, strength, ductility, and weldability in 
comparison to other wrought alloys such as Nimonic 105, Haynes 263, and Inconel 740 among others. This nickel based superalloy is conventionally wrought processed, contains typical amounts of $\mathrm{Cr}, \mathrm{Mo}$, and $\mathrm{Co}$ and is strengthened mainly by gamma prime precipitation from the addition of $\mathrm{Al}$ and $\mathrm{Ti}$. It has been well established that a balance of $\mathrm{Al}$ and $\mathrm{Ti}$ is crucial in order to maintain a low gamma/gamma prime misfit for optimal creep performance in nickel based superalloys [4]. In this work we closely examine the role of chemistry variation within the alloy specification as it applies to alloy performance.

\section{Experimental}

Computational thermodynamic modeling tools (Thermo-Calc) were first used to model the alloy phase contents at temperature to ensure the comparison of alloys with differing chemistries yet identical phase contents. Each heat of Haynes 282 was formulated from high purity raw materials. The alloys were designed with either the $\mathrm{Ti}$ or $\mathrm{Al}$ set to a low level and the other gamma prime stabilizer was adjusted such that the amount of gamma prime remained identical for both. The balance of the alloy constituents were set to the nominal Haynes 282 chemistry. The gamma prime misfit of each alloy was determined computationally using JMatPro software [5]. Each heat was melted in a vacuum induction furnace and cast with $50^{\circ} \mathrm{C}$ superheat above the Thermo-Calc predicted liquidus for each formulation. A $75 \mathrm{~mm}$ diameter round graphite mold was employed which also incorporated a zirconia wash coat to prevent the pickup of additional carbon. After casting, the hot-tops of each ingot were removed followed by a $2 \mathrm{~mm}$ thick diametrical slice for chemical analysis. The transition element chemistries were determined by wavelength dispersive x-ray florescence with a Rigaku ZSX Primus II utilizing NIST traceable standards (reported values are accurate to $0.01 \mathrm{wt} \%$ ); carbon chemistries were determined with a LECO CS444LS using NIST certified standards (reported values are accurate to $0.002 \mathrm{wt} \%$ ). To ensure the fidelity of experiments, a multi-step homogenization heat treatment [6] was used to better disperse the alloy constituents and thus reduce segregation and improve mechanical performance prior to hot working. The homogenized ingots were bagged in protective stainless steel foil pouches and preheated at $1175^{\circ} \mathrm{C}$ for 3 hours prior to fabrication. Hot working, using a scaled down version of industrial techniques, namely forging and rolling, was employed to fabricate the round ingots into slab shapes, which were ultimately hot worked to a thickness of approximately $10 \mathrm{~mm}$. The slabs were given a peak age heat treatment consisting of $1050^{\circ} \mathrm{C} / 2 \mathrm{~h} / \mathrm{AC}+1010^{\circ} \mathrm{C} / 2 \mathrm{~h} / \mathrm{AC}+788^{\circ} \mathrm{C} / 8 \mathrm{~h} / \mathrm{AC}$ and were cut into tensile bar blanks which were subsequently machined into cylindrical geometry tensile specimens which employed an $\mathrm{L}=4 \mathrm{D}$ geometry. Tensile and creep testing were performed at $800^{\circ} \mathrm{C}$ with instrumented data acquisition. Spent creep samples were then sectioned parallel to the test axis, ground to about mid-plane and polished via conventional metallographic procedures. The cross sections were imaged by SEM with a combination of secondary electron (SE) and backscatter electron (BSE) techniques.

\section{Results and Discussion}

With the balance of the alloy additions set to nominal, the Al or Ti concentration was set to a low level and the other $\gamma$ stabilizer was adjusted such that the amount of $\gamma$ was identical for both. Figure 1 shows a plot of weight fraction of phases vs. temperature for a Haynes 282 alloy with low $\mathrm{Al}$, and $\mathrm{Ti}$ adjusted to obtain 16.8 wt. $\% \gamma^{\prime}$ at $800^{\circ} \mathrm{C}$, which will be referred to as $\mathrm{H} 282-\mathrm{B}$, henceforth. Figure 2 shows a plot of weight fraction of phase versus temperature for a Haynes 
282 alloy with low $\mathrm{Ti}$, and $\mathrm{Al}$ adjusted to obtain $16.8 \mathrm{wt} . \% \gamma^{\prime}$ at $800^{\circ} \mathrm{C}$, which will be referred to as H282-C, henceforth. The two plots appear to predict essentially the same amount of equilibrium constituent phases including $\mathrm{M}_{6} \mathrm{C}$ and $\mathrm{M}_{23} \mathrm{C}_{6}$ carbides and $\mathrm{Mu}$ phase. However, close examination reveals that the amount of $\gamma^{\prime}$ increases as temperature decreases in a similar, but not identical way such that at $500^{\circ} \mathrm{C}$ alloy $\mathrm{H} 282-\mathrm{C}$ would have 24.7 wt. $\% \gamma^{\prime}$ while alloy H282-B would have $23.4 \mathrm{wt}$. $\% \gamma^{\prime}$. Thus it is important that these two alloys be compared at $800^{\circ} \mathrm{C}$ where they were designed to have an identical $\gamma^{\prime}$.

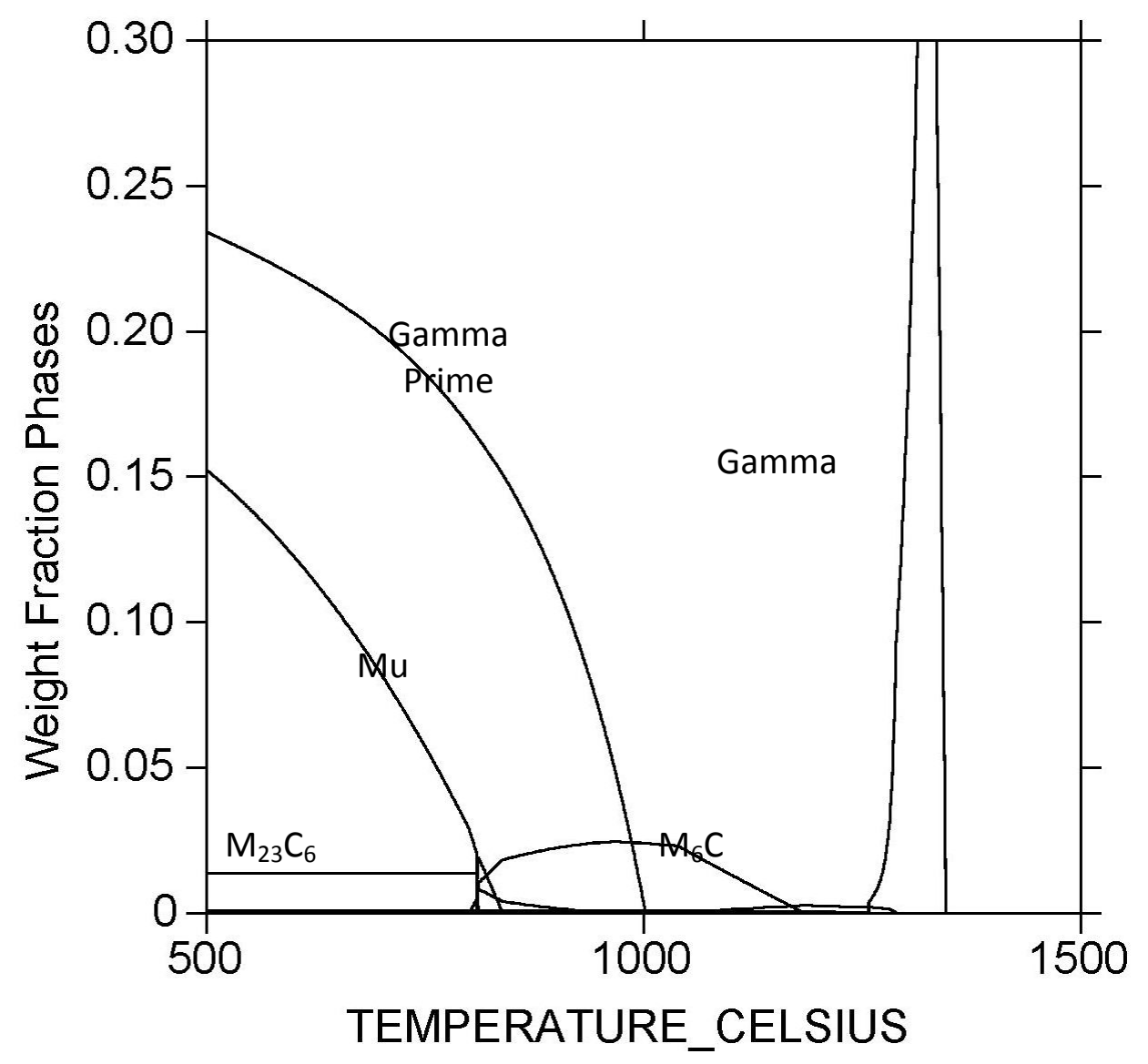

Figure 1: The equilibrium weight fraction of phases is plotted as a function of temperature for the alloy with low $\mathrm{Al}(\mathrm{H} 282-\mathrm{B})$. 


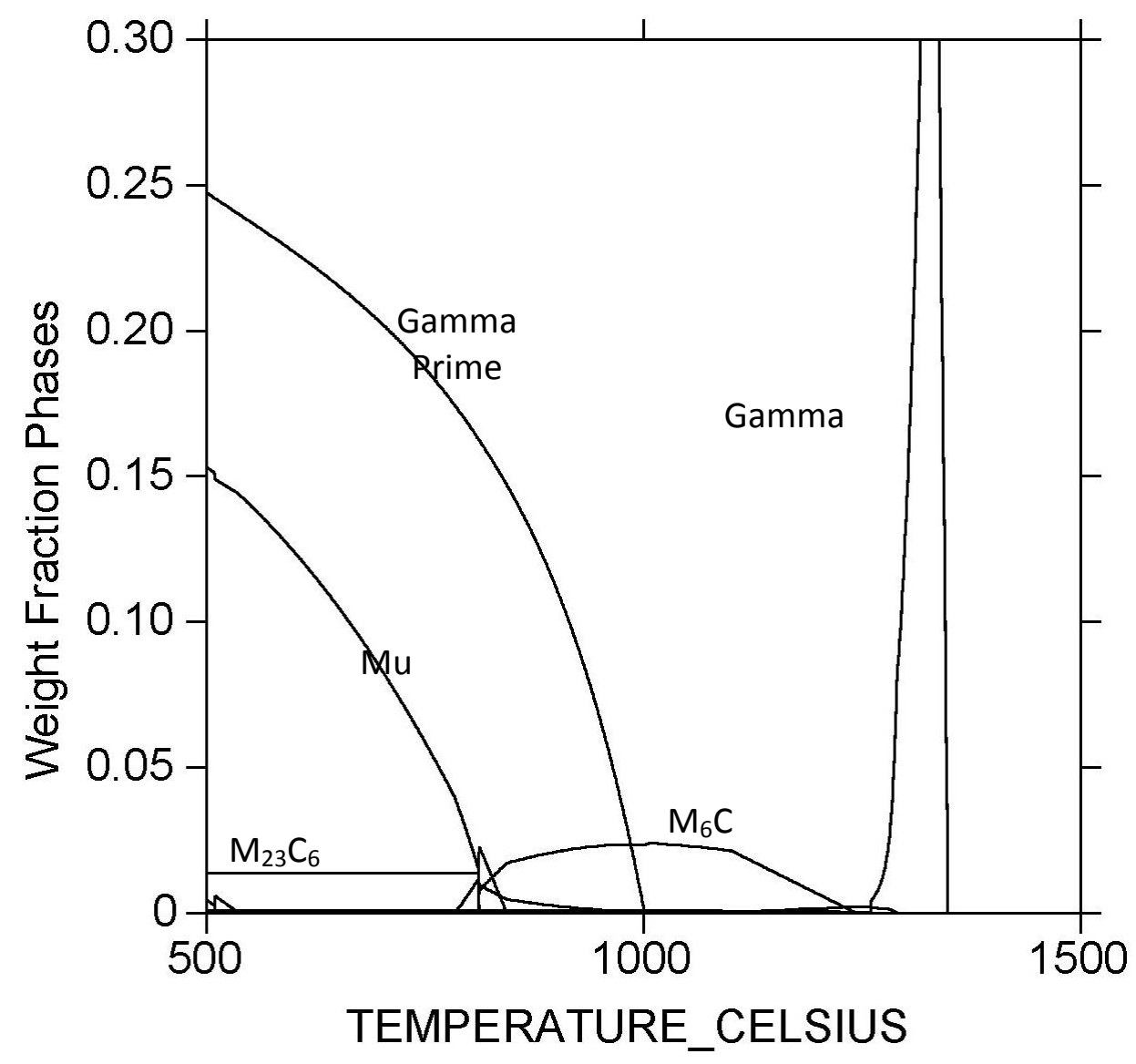

Figure 2: The equilibrium weight fraction of phases is plotted as a function of temperature for the alloy with low Ti (H282-C).

\section{Chemistry}

The actual chemistries varied slightly from the aims with minimal losses of both $\mathrm{Al}$ and $\mathrm{Ti}$ (Table I). For example, H282-B contained 1.27 wt. \% Al and 2.22 wt. \% Ti versus the 1.38 wt. $\% \mathrm{Al}$ and 2.24 wt. \% Ti design chemistries. Likewise, H282-C contained 1.54 wt. \% Al and 1.94 wt. \% Ti versus the 1.65 wt. $\% \mathrm{Al}$ and $1.97 \mathrm{wt}$. $\%$ Ti design chemistries. This resulted in a reduction in the amount of predicted $\gamma^{\prime}$ at $800^{\circ} \mathrm{C}$ slightly from the design value, $16.8 \mathrm{wt} \%$ to 15.8 wt. $\%$ and 15.6 wt. \% for alloys $\mathrm{B}$ and $\mathrm{C}$, respectively, which are being considering identical for the purposes of this comparison. 
Table I. The experimental alloy chemistry of each heat is given below along with the Haynes 282 chemistry range.

\begin{tabular}{cccccccccccc}
\hline Alloy & Ni & Cr & Co & Mo & Ti & Al & Fe & Mn & Si & C & $\begin{array}{c}\text { B } \\
\text { ppm }\end{array}$ \\
\hline Nominal & Bal & $18.5-$ & $9-$ & $8-$ & $1.9-$ & $1.38-$ & $1.5^{*}$ & $0.3^{*}$ & $0.15^{*}$ & $0.04-$ & $30-$ \\
& & 20.5 & 11 & 9 & 2.3 & 1.65 & & & & 0.08 & 50 \\
H282-B & Bal & 19.22 & 9.86 & 8.49 & 2.22 & 1.27 & & 0.25 & 0.15 & 0.08 & 100 \\
H282-C & Bal & 19.19 & 9.85 & 8.50 & 1.94 & 1.54 & & 0.25 & 0.14 & 0.08 & 100 \\
\hline
\end{tabular}

*Maximum value

\section{Mechanical Test Results}

The results from the tensile tests performed at $800^{\circ} \mathrm{C}$ are presented in Table II. The results of both alloys appear to be nearly identical with perhaps a slightly greater ductility in the high $\mathrm{Al}$ alloy $(\mathrm{H} 282-\mathrm{C})$.

The results from the creep tests performed at $800^{\circ} \mathrm{C}$ are presented in Table III. The minimum creep rates and rupture times were determined for each stress level. Creep stress exponents were calculated by applying a power law curve to the log-log plot of minimum creep rate versus stress. Over the stress range of $200-414 \mathrm{MPa}$ at $800^{\circ} \mathrm{C}$, creep stress exponents of 8.6 and 6.4 were calculated for the H282-B and H282-C alloys, respectively. These values of creep stress exponent suggest dislocation climb would be the dominant creep deformation mechanism during steady state creep in the case of a single phase metal or alloy [7]. The creep stress exponents calculated also suggest that the same deformation mechanism is active over the limited stress range examined at $800^{\circ} \mathrm{C}$, for each alloy. Each of the samples in this study were taken to rupture under constant load, therefore interruption of the creep deformation experiments during secondary, or steady state creep, was not performed. The high stress and high temperature conditions these creep tests were performed at were chosen so as to highlight any direct effects the change in lattice mismatch due to differing Ti and Al contents may have on the alloy, as opposed to deterimining dominant secondary steady state creep deformation mechanisms. The minimum creep rates reported in Table III are, therefore, not representative of a constant stress condition, and the microstructural deformation features discussed, henceforth, represent damage accumulated during the primary, secondary, and tertiary stages of creep. Due to the large ductility and reduction in area displayed by these alloys at $800^{\circ} \mathrm{C}$ (see Table II), constant stress creep testing would be required to accurately determine dominant secondary creep deformation mechanisms in alloy 282.

Table II: The hot tensile properties at $800^{\circ} \mathrm{C}$ are given in the table below.

\begin{tabular}{ccccc}
\hline & Yield (MPa) & UTS (MPa) & Reduction of Area (\%) & Elongation (\%) \\
\hline H282-B & 566 & 687 & 20.4 & 19.6 \\
H282-C & 586 & 689 & 21.7 & 25.9 \\
\hline
\end{tabular}

Table III. The creep properties at $800^{\circ} \mathrm{C}$ are given in the table below. 


\begin{tabular}{ccccc}
\hline & $\begin{array}{c}\text { Stress, } \\
\text { MPa }\end{array}$ & $\begin{array}{c}\text { Minimum Creep Rate, } \\
\mathbf{s}^{-1}\end{array}$ & $\begin{array}{c}\text { Creep Stress } \\
\text { Exponent }\end{array}$ & $\begin{array}{c}\text { Time to Rupture, } \\
\text { hours }\end{array}$ \\
\hline \multirow{4}{*}{ H282-B } & 200 & $1.70 \times 10^{-09}$ & & 1,171 \\
& 276 & $1.60 \times 10^{-08}$ & & 212 \\
& 345 & $6.30 \times 10^{-08}$ & 8.60 & 54 \\
\hline \multirow{3}{*}{ H282-C } & 414 & $1.30 \times 10^{-06}$ & & 15 \\
& 200 & $2.60 \times 10^{-09}$ & & 1,113 \\
& 345 & $1.60 \times 10^{-08}$ & 6.4 & 156 \\
& 414 & $1.30 \times 10^{-07}$ & & 46 \\
\hline
\end{tabular}

In the case of these multiphase alloys, microstructural examination of the grip and gage sections of the ruptured creep specimens provided insight into the creep performance displayed by each alloy. Figures 3 and 4 show images from within the bulk of the creep samples from both the grip and gage sections of the samples tested at $800^{\circ} \mathrm{C}$. For the duration of the creep tests, the grains within the post-mortem grip portions retained their equiaxed geometry and displayed no slip bands, or cracking, in comparison to the grains within the gage section which show grain rotation, planar slip bands within individual grains, and profuse cracking along the $\gamma$ grain boundaries. The maximum grain boundary crack widths were displayed by those $\gamma$ grain boundaries orientated perpendicular to the tensile axis.

For the stress range of $200-414 \mathrm{MPa}$ at $800^{\circ} \mathrm{C}$, crack growth along the $\gamma$ grain boundaries was observed to be the main form of damage accumulation during creep for each of the alloys, regardless of stress level. Examination of the grip and gage microstructure of each of these samples revealed that very fine recrystallized grains (on the size scale of up to a few $\mu \mathrm{m}$ in diameter), and what is suggested to be $\mathrm{M}_{6} \mathrm{C}$ carbide, are present along each $\gamma$ grain boundary. The carbides appear to be $\mathrm{M}_{6} \mathrm{C}$ carbides based upon the results of the thermodynamic modeling (Figures 1 and 2), their bright contrast when imaged using backscattered electrons, and a consistently high concentration of Mo found in these carbides, relative to the rest of the microstructure, when measured by EDX. The size of the recrystallized grains present on the $\gamma$ grain boundaries increased with increasing exposure time at $800^{\circ} \mathrm{C}$. Figure 5 shows a BSE image from a H282-C sample that ruptured after 1113 hours under a stress of $200 \mathrm{MPa}$ at $800^{\circ} \mathrm{C}$. The grain boundary crack in Figure 5 is surrounded by recrystallized $\gamma$ grains that appear to be free of both the $\gamma^{\prime}$ and the deformation features which are present within the rest of the $\gamma$ grains in the microstructure. Therefore, the presence of these low dislocation density, $\gamma$-free recrystallized grains on the $\gamma$ grain boundaries provides an ideal percolation path for the growth of cracks that nucleate during creep deformation. However, since the creep experiments were not creep interruption experiments, it is not possible to differentiate which stage of the creep deformation the initiation of the cracking occurred. It is possible 

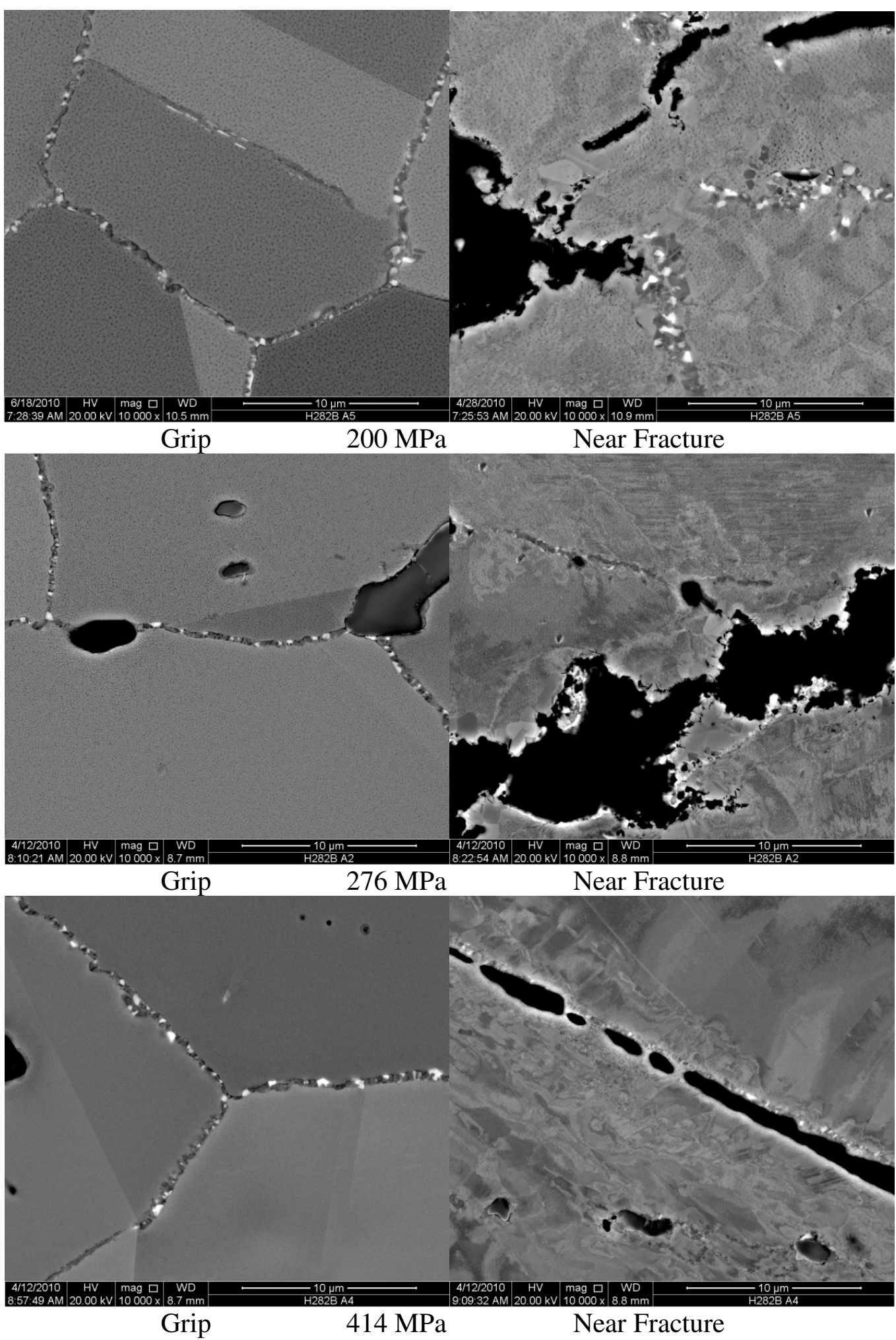

Figure 3: SEM images of grip sections (left) and near fracture regions (right) of creep specimens from alloy H282-B tested at 200, 276 and $414 \mathrm{MPa}$ (top, middle and bottom respectively). 

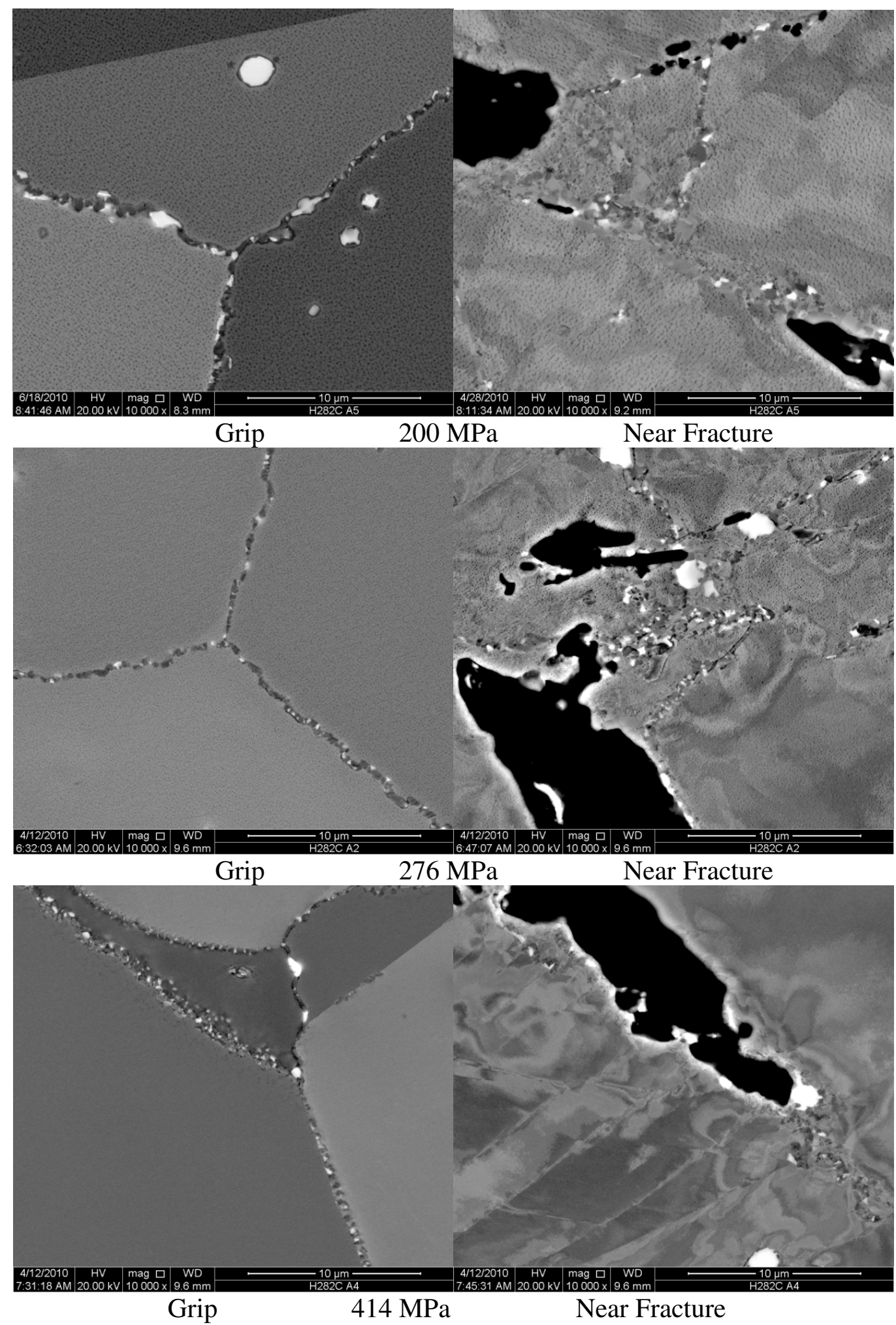

Figure 4: SEM images of grip sections (left) and near fracture regions (right) of creep specimens from alloy $\mathrm{H} 282-\mathrm{C}$ tested at 200, 276 and $414 \mathrm{MPa}$ (top, middle and bottom respectively). 


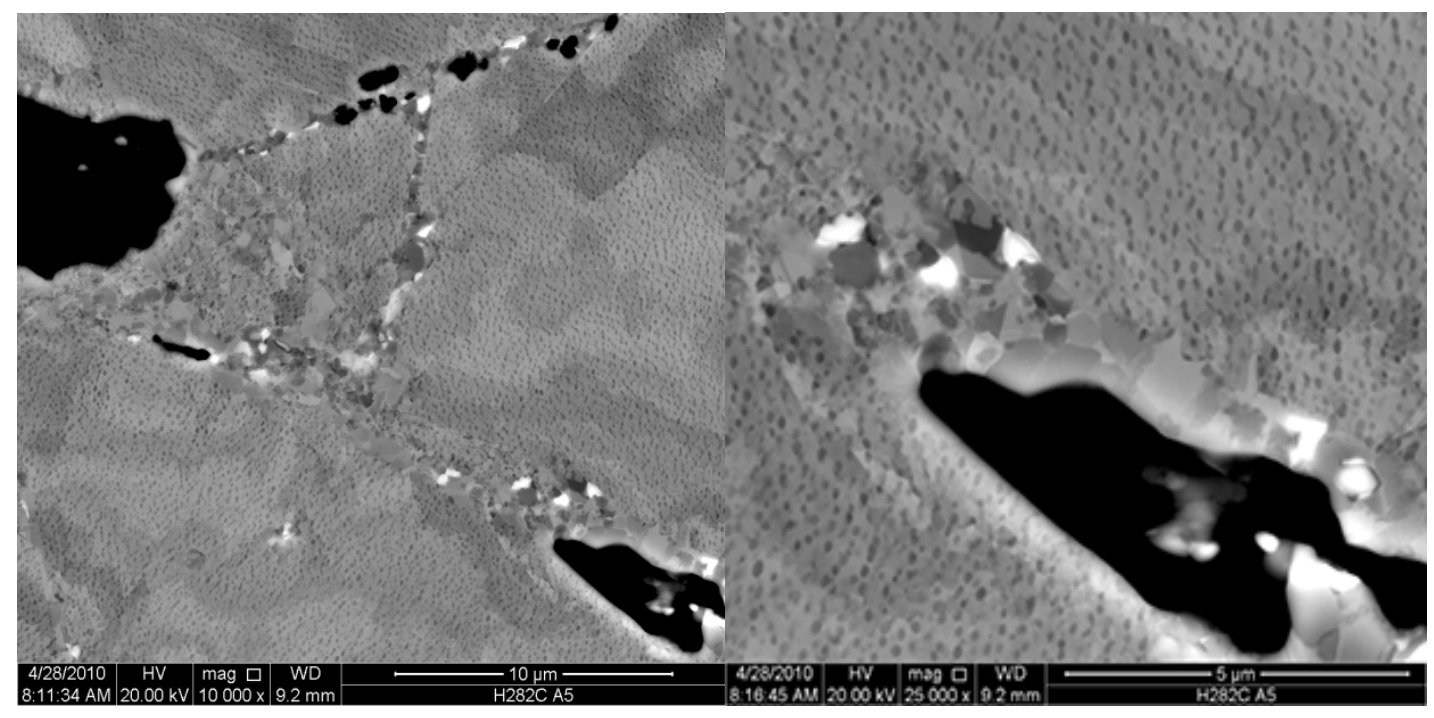

Figure 5: Recrystallization grains are present along gamma grain boundaries and grain boundary cracks and evidence of the onset of rafting of the gamma prime phase after creep deformation in alloy $\mathrm{H} 282-\mathrm{C}$ tested to failure at $200 \mathrm{MPa} / 800^{\circ} \mathrm{C}$.

that the post mortem cracking observed did not occur until the onset of tertiary creep, and then accounted for the tertiary creep strain, but is not representative of the dominant deformation mechanism operative during true steady state creep in alloy 282. Evidence of the onset of rafting of the $\gamma$ due to the applied stress during creep is also visible in Figure 5.

The calculated amount of $\gamma^{\prime}$ lattice mismatch with the matrix phase for the two alloys in the heat treated condition is presented in Figure 6. Both alloys show a slight negative mismatch ranging from about $-0.1 \%$ to about $-0.14 \%$ at $800^{\circ} \mathrm{C}$. This negative mismatch appears to have minimal consequences on morphology since both alloys contain spherical $\gamma^{\prime}$ precipitates prior to creep exposure. The effect of high and low Ti and Al contents in producing the same amount of $\gamma^{\prime}$, but with a $40 \%$ difference in $\gamma^{\prime}$ lattice mismatch, did not appear to have a significant effect on the creep behavior displayed, at the SEM scale of microstructural characterization. Similar rupture lives at the same stress level and similar creep stress exponents suggest the same deformation mechanism are dominant during secondary creep, and similar modes of deformation and damage accumulation suggest that the features of the microstructure (fine recrystallized $\gamma$ grains saturating $\gamma$ grain boundaries) outweigh the influence of any intrinsic strengthening effects dictated by a different degree of lattice mismatch due to chemistry differences of $\gamma^{\prime}$ in each alloy. The impact on low stress, long life creep samples remains to be seen.

It is of interest to note that the recrystallized grains along the gamma grain boundaries do not appear during the first solution heat treatment step at $1150^{\circ} \mathrm{C}$. It was noted, however, that they appeared during the second solution heat treatment step at $1010^{\circ} \mathrm{C}$, prior to aging the alloy to precipitate $\gamma^{\prime}$ at $788^{\circ} \mathrm{C}$ in both alloys (see Figure 7). Further investigation into a thermomechanical treatment to alleviate the presence of these grains, and therefore, improve the creep resistance of this alloy is warranted. Removal of these fine grains from the microstructure 
may provide a more sensitive medium for isolating the effect due to lattice mismatch of $\gamma^{\prime}$ due to differing $\mathrm{Ti}$ and $\mathrm{Al}$ contents in alloy $\mathrm{H} 282$ on creep performance.

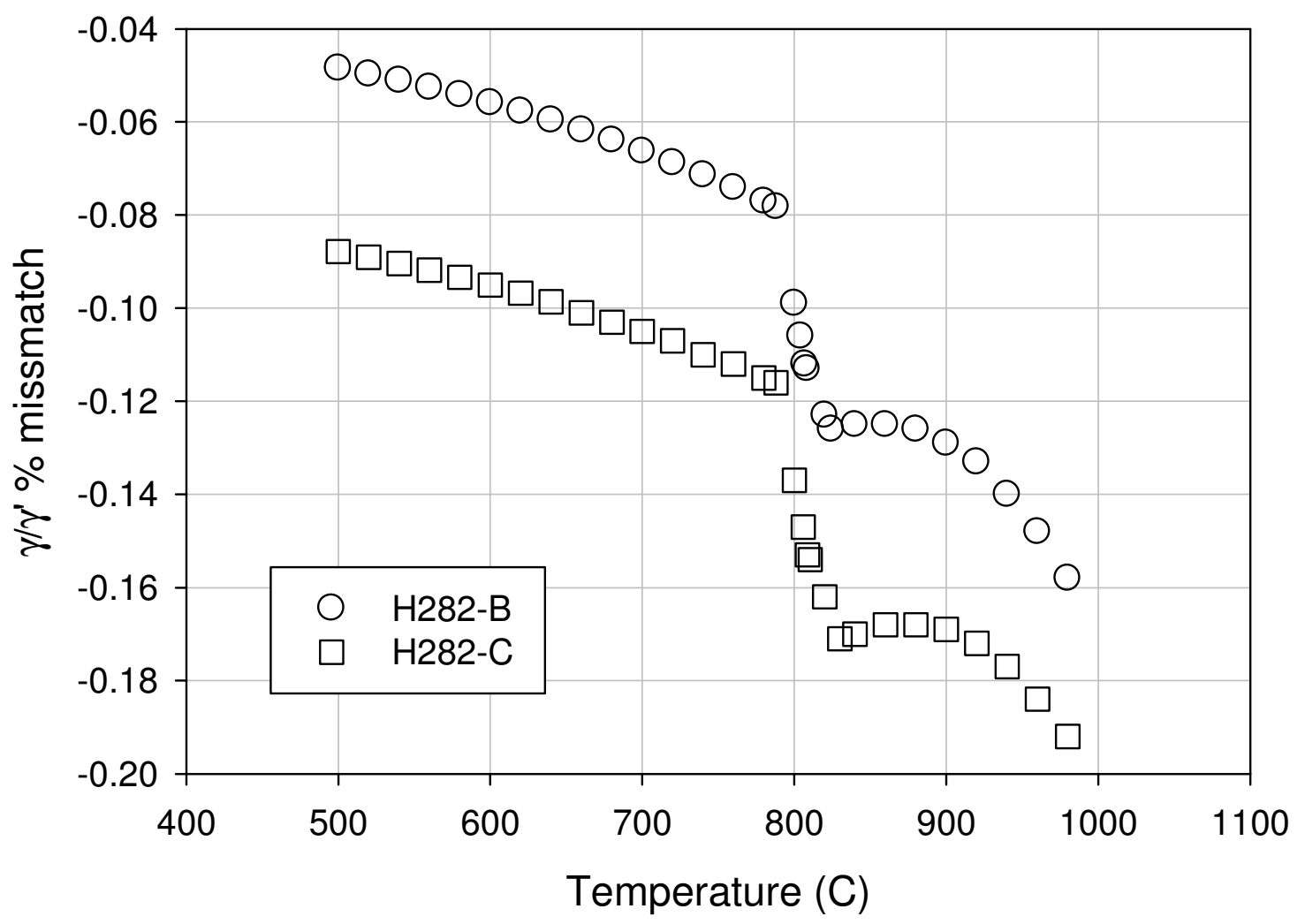

Figure 6: The gamma prime misfit with the matrix gamma phase is shown above for both alloys as a function of temperature (calculated with JMatPro software). 

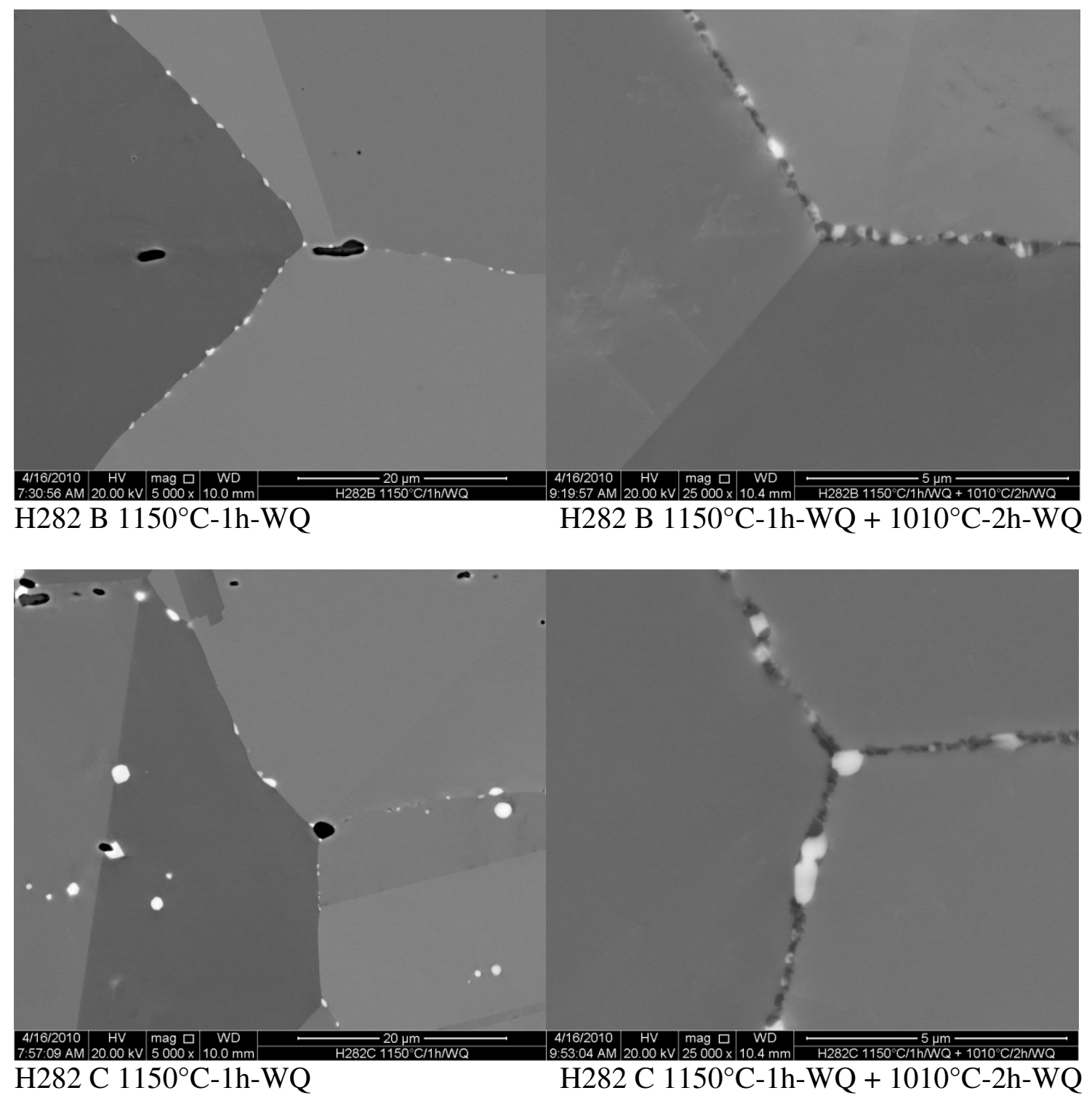

Figure 7: These BSE micrographs illustrate that the fine recrystallized grains present on the gamma grain boundaries are incorporated into each alloy microstructure during the second solution heat treatment.

\section{Conclusions}

The effect of high $\mathrm{Al}$ or Ti with the same $\gamma^{\prime}$ content in alloy Haynes 282 was evaluated. Limited hot tensile and creep testing suggest that the alloy is insensitive to changes in the content of these two elements within the alloy specification. However, it was observed that creep deformation was concentrated within fine recrystallized grains which occurred along the prior $\gamma$ grain boundaries as a result of the solution treatment at $1010^{\circ} \mathrm{C}$. Avoidance of these fine grains may lead to an increase in creep life of the alloy and perhaps a clearer distinction between alloys with differing $\gamma$ misfit parameters. 


\section{References}

1. R. Viswanathan et al., Journal of Materials Engineering and Performance, 14 (3) (2005), 281-292.

2. R. Viswanathan, A.F. Armor and G. Booras, Power (4) (2004) 42-49.

3. http://www.netl.doe.gov/technologies/coalpower/advresearch/Ultrasupercritical.html

4. Superalloys II, C.T. Sims, N.S. Stoloff, and W.C. Hagel, eds., John Wiley \& Sons, New York, NY, (1987).

5. Jablonski and Cowen, Met Trans 40B 182 (2009).

6. N. Saunders, Z. Guo, X. Li, A.P. Miodownik and J.-Ph. Schillé, Superalloys 2004, eds. K.A. Green, T.M. Pollock, H. Harada, T.E. Howson, R.C. Reed, J.J. Schirra, and S. Walston, (Warrendale, PA: TMS, 2004), 849.

7. R.W. Evans and B. Wilshire, Creep of Metals and Alloys, The Institute of Materials, London, (1985). 